\title{
Leadership and Overcoming Coordination Failure with Asymmetric Costs
}

\author{
Jordi Brandts, David J. Cooper and Enrique Fatas
}

May 12, 2006

\begin{abstract}
We study how the heterogeneity of agents affects the extent to which changes in financial incentives can pull a group out of a situation of coordination failure. We focus on the connections between cost asymmetries and leadership. Experimental subjects interact in groups of four in a series of weak-link games. The treatment variable is the distribution of high and low effort cost across subjects. We present data for one, two and three low-cost subjects as well as control sessions with symmetric costs. The overall pattern of coordination improvement is common across treatments. Early coordination improvements depend on the distribution of high and low effort costs across subjects, but these differences disappear with time. We find that initial leadership in overcoming coordination failure is not driven by low-cost subjects but by subjects with the most frequent cost. This conformity effect can be due to a kind of group identity or to the cognitive simplicity of acting with identical others.
\end{abstract}

Keywords : Experiments, Coordination, Organizational change, Heterogeneous agents, Leadership

JEL Classification Codes : C70, C90, D63, D64

\section{Acknowledgements}

Financial support by the Spanish Ministerio de Educación y Ciencia and the Barcelona Economics Program of CREA is gratefully acknowledged. Remaining errors are ours.

\section{Authors}

\begin{tabular}{|c|c|c|}
\hline Jordi Brandts & David J. Cooper & Enrique Fatas \\
\hline Institut d'Anàlisi Econòmica, CSIC & Department of Economics & LINEEX \\
\hline Campus UAB & Weatherhead School of & Facultad de Economía \\
\hline 08193 Bellaterra (Barcelona) & Management & Campus Tarongers \\
\hline \multirow[t]{4}{*}{ Spain } & Case Western Reserve University & Universidad de Valencia \\
\hline & 10900 Euclid Avenue & 46022 Valencia \\
\hline & Cleveland, OH 44106-7206 & Spain \\
\hline & USA & \\
\hline phone $+34-93-5806612$ & Phone: 1-216-3684294 & phone $+34-958-249605$ \\
\hline fax $+34-93-5801452$ & Fax: 1-216-3685039 & fax $+34-958-249995$ \\
\hline jordi.brandts@uab.es & david.cooper@case.edu & fatas@uv.es \\
\hline
\end{tabular}


Dedication: We would like to dedicate this paper to the memory of Ray Battalio. Beyond his many contributions to experimental economics, including pioneering studies of coordination games that greatly influenced the work reported here, Ray was a wonderful friend and colleague. Experimental economics will miss him, as will we.

\section{Introduction}

Laboratory research has contributed considerably to a better understanding of coordination problems in environments that can be represented by games with multiple equilibria. The control and replicability of the lab has allowed a systematic analysis of coordination difficulties in a variety of situations. ${ }^{1}$ One of the most interesting types of coordination games is the minimum or weak-link game ${ }^{2}$ in which the output of a group is determined by the minimum effort of all group members. In a seminal paper Van Huyck, Battalio and Beil (1990) first studied this game and reported the then surprising result of very considerable coordination failure. The weak-link game can be seen as a good representation of production settings with complementarities and has been widely used to study issues of underperformance in companies and other organizations. ${ }^{3}$. Our study takes the results about coordination failure in the weak-link game as a starting point for an analysis of the process through which organizations can escape such performance traps. The focus here is on situations in which players have asymmetric effort costs

The main motivation for our work stems from the potential connections between asymmetries and leadership. When a group is stuck in a coordination trap somebody has to take action to initiate the escape from such a situation. The problem consists fundamentally in changing the beliefs that the people involved have about others' beliefs and actions. Brandts and Cooper (2006) show that, with symmetric costs, successful escapes from coordination traps take place gradually with some people acting as leaders who pull laggards after them. In this process subjects face an additional coordination problem of determining who the leaders ought to be. In principle any of those involved could take actions to try to change others' state of mind.

\footnotetext{
${ }^{1}$ See Ochs (1995) and Camerer (2003) for recent surveys.

${ }^{2}$ Van Huyck et al (1990) introduced this class of coordination games as the "minimum game." Camerer and Knez (1994) coined the more evocative moniker "weak-link game" which we use.

${ }^{3}$ See Camerer and Knez (1994 and 2000), Weber, Rottenstreich, Camerer and Knez (2001), Bornstein, Gneezy, and Nagel (2002), Weber, Camerer, and Knez (2004), Blume and Ortmann (2005), Croson, Fatas, and Neugebauer, Fatas, Neugebauer and Perote (2006), and Weber (2006).
} 
However, if players have different characteristics then these can function as coordination devices for solving the problem of who goes first in raising performance levels. The work we present in this paper starts from the conjecture that asymmetric effort costs may play a role in overcoming coordination failure beyond the direct effect on incentives. The cost differences may point to some of the players as "natural" leaders. Differences in effort costs imply differences in earnings in the different Nash equilibria. Intuition suggests that players with the lowest effort costs should act as leaders in pulling a group out of a performance trap. As a consequence, moves to overcome coordination failure may be more successful in asymmetric than in symmetric costs groups

We find that improvements in coordination following a change in incentives initially depend on effort cost asymmetries, but not for the reason hypothesized above. Leadership in overcoming coordination failure is driven not by low-cost subjects, but rather by subjects with the most frequent cost. This conformity effect can be due to a kind of group identity or to the cognitive simplicity of acting with identical others. Over time the effect of asymmetric effort costs largely vanishes.

Section 2 introduces the game we study, the turnaround game. Section 3 describes our experimental design and summarizes the primary research questions arising from our design. Section 4 presents our procedures. Section 5 reports the results and Section 6 concludes.

\section{The Turnaround Game}

The "turnaround game" played by subjects in our experiments can be thought of as representing a stylized model of a firm that suffers low performance and is trying to improve over time. This firm consists of a number of employees who choose among different effort levels in a number of consecutive periods. The turnaround game confronts employees with the dynamic problem of overcoming a history of coordination failure, rather than with the simple static problem of choosing an effort level once.

The turnaround game embodies three basic design choices. First, the firm's technology has a weak-link structure, with productivity (as well as profitability) depending in every time period on the minimum effort chosen by an employee. Second, the firm manager only observes the minimum effort selected, since it determines the output, but employees can observe all effort levels selected. Third, the firm manager rewards employees with bonuses based on the minimum 
effort observed and is able to change the bonus rate but cannot otherwise influence the employees' choices. In what follows we present the main features of the turnaround game in more detail.

An experimental firm in the turnaround game consists of a fixed grouping of four employees who interact for thirty consecutive rounds, broken into three ten-round blocks. Each block starts with the announcement of a common bonus rate (B) for the ten rounds of the block that determines how much additional pay each employee receives for each unit increase in the minimum effort. All four employees observe B and then simultaneously choose effort levels, where $E_{i}$ is the effort level chosen by the $i^{\text {th }}$ employee. We restrict an employee's effort to be in ten hour increments: $\mathrm{E}_{\mathrm{i}} \in\{0,10,20,30,40\}$. Intuitively, employees spend forty hours per week on the job, and effort measures the number of these hours that they actually work hard rather than loafing. 4 Employees' payoffs are determined by Equation 1 below. Note that effort is costly, with $\mathrm{C}_{\mathrm{i}}$ denoting the cost of a unit of effort for the $i^{\text {th }}$ employee. The cost of effort of each employee is held fixed throughout an experimental session. All payoffs are denominated in "experimental currency units" (ECUs). These were converted to monetary payoffs at a rate of 1 euro equals 500 ECUs:

$$
\text { Employee } \mathrm{i}: \pi_{\mathrm{e}}^{\mathrm{i}}=200-\mathrm{C}_{\mathrm{i}} \mathrm{E}_{\mathrm{i}}+\left(\mathrm{B} \times \min _{\mathrm{j} \in\{1,2,3,4\}}\left(\mathrm{E}_{\mathrm{j}}\right)\right) \quad \text { (eq. 1) }
$$

In all our treatments the average cost of effort equals $7\left(\right.$ e.g. $\frac{1}{4}\left(\mathrm{C}_{1}+\mathrm{C}_{2}+\mathrm{C}_{3}+\mathrm{C}_{4}\right)=7$ ). The four treatments differ only in the distribution of these costs over employees. In all of the experiments described below employees initially receive a low bonus rate of $\mathrm{B}=8$, which in round 11 is increased to $\mathrm{B}=14$. As a useful example for thinking about the coordination problem here as well as developing some initial hypotheses about the impact of asymmetric costs, consider one of our treatments in which $\mathrm{C}_{1}=1$ and $\mathrm{C}_{2}=\mathrm{C}_{3}=\mathrm{C}_{4}=9$. With $\mathrm{B}=14$, the payoff tables shown in Table 1 result. The table on the left is for the low cost type and the table on the right applies to the three high cost types. If $\mathrm{C}_{\mathrm{i}}<\mathrm{B}$ for all $\mathrm{i} \in\{1,2,3,4\}$, as in this example with $B=14$, the resulting game is a weak link game. Standard game theoretic analysis provides little insight into the likely outcome of such games as coordinating on any of the five

\footnotetext{
${ }^{4}$ In the experiments, terms that we judged to have strong connotations such as "effort" and "loafing" were not used. Employees were told that they spent 40 hours per week on the job, and that these hours could either be allocated to Task A or Task B. Task A plays the role of effort and Task B plays the role of loafing.
} 
available effort levels corresponds to a Nash equilibrium. If $\mathrm{C}_{\mathrm{i}}>\mathrm{B}$ for any $\mathrm{i} \in\{1,2,3,4\}$, as occurs in this example when $\mathrm{B}=8$, then the unique Nash equilibrium is for all employees to choose effort level zero.

\section{(Table 1 Here)}

In the initial phase with $\mathrm{B}=8$, choosing an effort level of 0 is a dominant strategy for the three high cost types. It is therefore highly likely that employees enter the second phase of the experiment, when the bonus rate increases to $\mathrm{B}=14$, coordinated on the worst possible equilibrium of the new game where all choose effort level 0.

Once the bonus is increased to $\mathrm{B}=14$ the new game is a weak-link game. All employees can now profit from raising their effort levels, but only if all other employees raise their effort levels as well. For each of the high cost types $\left(\mathrm{C}_{2}=\mathrm{C}_{3}=\mathrm{C}_{4}=9\right)$ the incentives to increase their effort beyond the minimum are weak and the risks are high. An employee who considers raising his effort from 0 to 10 knows that this action causes a certain loss of 90 ECUs due to the cost of increasing effort. If the other three employees match this increase, his net gain is only 50 ECUs beyond the 200 ECUs he gets without risk by choosing 0. For the proposed change in his effort level from 0 to 10 to have an immediate positive return, the employee must believe the probability of all three other subjects simultaneously raising their efforts from 0 to 10 exceeds 9/14. Treating the other three subjects as statistically independent, this translates into requiring at least an $86 \%$ chance of increased effort for each of the other three subjects. ${ }^{5}$ A high cost type must be almost certain that the other subjects will increase their efforts for such an increase to be worthwhile for him.

The incentives are kinder for the low cost type $\left(\mathrm{C}_{1}=1\right)$, as an increase to effort level 10 only entails a sure loss of 10 ECUs as opposed to a potential gain of 130 ECUs. Assuming the other three subjects are independent, this only requires a $42 \%$ chance of increased effort from each of the other three subjects for the low cost type to break even. At first sight this seems more promising than for the case of a high-cost type. However, the required increases must come entirely from high cost types who have poor incentives.

\section{Experimental Design and Research Questions}

The top portion of Table 2 summarizes the experimental design. The treatments differ only in the costs of effort. In all sessions, subjects (employees) played thirty rounds in fixed

\footnotetext{
${ }^{5}$ To derive this probability, solve for $\mathrm{p}$ such that $200=110 *\left(1-\mathrm{p}^{3}\right)+250 * \mathrm{p}^{3}$.
} 
groups (firms) of four. For the first ten rounds the bonus rate was set at $\mathrm{B}=8$. It was then raised to $\mathrm{B}=14$ for the remaining twenty rounds.

(Table 2 Here)

In control sessions all four employees had the same cost of effort: $C_{1}=C_{2}=C_{3}=C_{4}=7$. Consistent with the results of earlier work on the turnaround game with symmetric costs (Brandts and Cooper, 2006), we expected to see low average minimum efforts emerge over the first ten rounds. ${ }^{6}$ After the increase in the bonus rate we expected to see a sharp increase in average minimum effort although not to the level of perfect coordination (e.g. all employees choosing effort level 40).

A basic design choice we made was to hold the average cost of effort fixed at 7 across the three treatments and to vary the asymmetry of costs of effort. All three treatments have low and high cost types, but vary the number of each type. In the "one low, three high" treatment, $\mathrm{C}_{1}=1$ and $\mathrm{C}_{2}=\mathrm{C}_{3}=\mathrm{C}_{4}=9$. $^{7}$ These specific costs of effort were chosen to make the cost of the low cost type as low as possible while keeping all costs positive and the average cost equal to 7 . In the "three low, one high" treatment, $\mathrm{C}_{1}=\mathrm{C}_{2}=\mathrm{C}_{3}=5$ and $\mathrm{C}_{4}=13$. These costs are chosen to make the cost of the high cost type as large as possible while keeping all costs below the bonus rate (so that the game is a weak-link game) and the average cost equal to 7 . As a result the low cost employee in the "one low, three high" treatment has a lower cost than the three low cost employees in "three low, on high". For our third treatment, "two low, two high", we chose the following cost levels $\mathrm{C}_{1}=\mathrm{C}_{2}=5$ and $\mathrm{C}_{3}=\mathrm{C}_{4}=9$. There are other possible "two low, two high" cost distributions. However, note that our choice allows us to make comparisons across treatments of subjects who have the same cost of effort and bonus rate but are grouped with other employees that have a different distribution of costs of effort. Specifically, we can compare the behavior of low cost types in the "two low, two high" treatment with the behavior of low cost types in the "three low, one high" treatment as well as comparing the behavior of high cost types in the "two low, two high" treatment with the behavior of high cost types in the "three low, one high" treatment.

We can now formulate the following research questions:

\footnotetext{
${ }^{6}$ The payoff function in that case was $\pi_{\mathrm{e}}^{\mathrm{i}}=200-5 \mathrm{E}_{\mathrm{i}}+\left(\mathrm{B} \times \min _{\mathrm{j} \in\{1,2,3,4\}}\left(\mathrm{E}_{\mathrm{j}}\right)\right)$.

${ }^{7}$ The employee ID numbers are used for expositional convenience; these numbers were not shown to the subjects.
} 
- Is it easier to overcome coordination failure with asymmetric costs? If so, does relative frequency of low versus high cost types matter?

- In the asymmetric cost treatments, do differences in costs help determine which sujects take the role of leaders in reaction to the bonus increase?

A priori, we anticipated improved coordination following the bonus rate increase for all of the treatments, but expected the effect of increased bonuses to be particularly effective with asymmetric costs of effort. Beyond this, we speculated that attained coordination levels would be higher with fewer low cost employees (subject to having asymmetric effort costs).

These predictions were based on the central role of leadership in overcoming coordination failure and the likely effects of asymmetric costs on the incidence of leadership. Previous experiments with the turnaround game found that the process of overcoming coordination failure is typically gradual (Brandts and Cooper, 2006). In firms that successfully overcome coordination failure there is usually a group of employees who take a leadership role by increasing their effort levels before others and maintaining it for some time. Eventually laggards are pulled up to the leaders' effort levels. With symmetric costs, there are no externally visible characteristics to mark which employees should take this risky leadership role. Which subjects become the leaders is determined solely on the basis of the subjects' innate qualities for example, which subjects are particularly willing to bear risk or psychologically more inclined to taking the initiative than others. Asymmetric costs might help solve the additional coordination problem of leader selection by creating a focal point for who the leaders should be. As such we expected greater leadership and better coordination with asymmetric costs.

Low cost types are natural candidates to become leaders, as they face the least risk from leadership and have the largest potential gains. Building on this, intuition suggested that one lonely low cost employee naturally would have a stronger drawing power than two low cost employees, two more than three and finally three more than the identical four subjects in the control condition. In other words, having a relatively rare type that is particularly well suited to leadership might make it especially likely that an employee becomes a leader even if he was not naturally inclined to this role. As such we speculated that the impact of asymmetric costs would be decreasing in the number of low cost types. Our confidence in this prediction was tempered by other elements of the problem. In particular, Brandts and Cooper (2006) find, for the symmetric case, that multiple leaders are far more effective than a single leader in overcoming a 
history of coordination failure. Having more low cost types might make it less likely that any one low cost type became a leader, but might make it more likely that the necessary multiple leaders emerge.

\section{Procedures}

Sessions were run at the LINEEX computer lab of the University of Valencia. We aimed to gather data from twenty firms for each treatment, which generally required two sessions. The realized number of firms varies slightly across treatments due to random variations in how many subjects arrived for sessions.

Subjects were recruited from the undergraduate population of the University of Valencia, mainly among economics, business and law students. Students received an e-mail message announcing sessions. They then had to physically sign themselves in on a bulletin board. Subjects were only allowed to participate in a single session. For the most part, the experimental procedures were quite standard. At the beginning of each session subjects read the instructions directly from their computer screens. Before beginning to play, all subjects were asked to complete a short quiz about the payoffs and the rules of the experiment. The full text for the instructions and quiz for the "one low, three high" treatment is included as an appendix.

Rather than using abstract terminology we employ a corporate context. For example, the four players are explicitly referred to as "employees" and are told that they are working for a "firm." We avoided the use of terms with what we considered strong connotations. For example, instead of asking subjects to choose a level of "effort" they are asked to allocate time between "Activity A" and "Activity B," with Activity A playing the role of effort. We used a corporate context to make the instructions easier to understand for participants. While the use of meaningful context may have an impact on subjects' choices, any such effect would only affect our results if it interacted with changes in the costs of effort. ${ }^{8}$ It seems unlikely that any such interaction would occur.

The instructions stressed that firm membership remained fixed throughout the experiment. For experimenters who are used to worrying about repeated game effects, the use of fixed groups may seem like a strange design choice. However, the field settings that we are interested in simulating involve repeated interactions among the same agents. Repeated game effects and history dependence are presumably quite natural in these settings. Moreover, the

\footnotetext{
${ }^{8}$ Cooper and Kagel (2003) find that the use of meaningful context can speed up the development of strategic play.
} 
possibility of history dependence is necessary for the development of leadership by example in the turnaround game. Repeated interactions are therefore the appropriate case to study. ${ }^{9}$

In all rounds subjects knew their own cost of effort, the distribution of other employees' costs of effort (but not the cost of any particular employee), and the current bonus rate. At the beginning of each ten period block the experiment was paused and the bonus rate for the upcoming ten periods was announced on a special screen. Subjects knew that there would be a total of 30 rounds and that the bonus rate might change in future rounds. They did not know what future bonus rates would be. Other than the bonus rate, no detail of the experimental environment varied between blocks. In particular, subjects knew that the costs of effort would not be changing.

In each round the four employees of a firm simultaneously chose their effort levels for the round. The screen where subjects made this decision displayed the current bonus rate as well as a payoff table similar to the ones displayed in Table 1. This showed the employee's payoff as a function of their own effort level and the minimum effort level chosen by the other employees. This payoff table was automatically adjusted to reflect the current bonus rate. In treatments where costs of effort were asymmetric, paper copies of other employees' payoff tables were handed out as well. At the end of each round employees were told their effort level, their payoff for the round, and their running total payoff for the experiment. ${ }^{10}$ Separate windows on the feedback screen showed employees all four employees' effort levels for the round just completed as well as a summary of outcomes from earlier rounds. The four effort levels were sorted from lowest to highest. Subjects were not given any information about which employee had chosen which effort level, and therefore could neither track a particular employee across rounds nor observe any relationship between costs of effort and effort levels chosen.

At the end of the session, each subject was paid in cash for all rounds played plus a showup fee of five euros. Payoff was done on an individual and private basis. Recall that all payoffs are in "ECUs" which were converted to euros at a rate of one euro equals five hundred ECUs.

\footnotetext{
${ }^{9}$ Most existing studies of the weak-link game use fixed matching as we do. For one notable exception see Van Huyck et al (1990) - their Treatment C compares play for fixed and random pairings in two player weak-link games. For the final round of play, effort levels are significantly higher with fixed pairings than with random pairings.

${ }^{10}$ Employees were also given information on a fictitious manager for the firm. While not important for the current study, this allowed us to maintain parallelism with sessions where a fifth subject played as the firm manager (Brandts and Cooper, 2005).
} 
The average total payoff was $20.29 €$ and the average session lasted about 90 minutes. These earnings were sufficiently large to generate a good supply of subjects.

\section{Results}

A necessary condition for the experimental treatments to be of interest is that coordination failure occurs prior to the increase in the bonus rate. This occurs uniformly with asymmetric costs of effort, as the minimum effort equals 0 - the choice in the unique Nash equilibrium - in period 10 for all 61 firms in these treatments. Moreover, all four employees choose zero in period 10 for 44 of these 61 firms. In the control treatment with symmetric costs, the minimum effort equals 0 in period 10 for 16 of the 19 firms and all four employees choose zero in 9 of the 19 groups. Weaker convergence in the control treatment with symmetric costs is unsurprising as it is not the unique Nash equilibrium for all employees to choose zero. None the less, even in the control treatment firms almost always face a history of coordination failure when the bonus rate is increased.

The bottom half of Table 2 shows descriptive statistics on how outcomes respond to the change in bonus rates for periods $11-30$. Detailed pictures of how average minimum effort and average effort evolve over time are given by Figures 1 and 2.

\section{(Figures 1 and 2 here)}

Looking at Figure 1, we see that average minimum effort jumps in all four treatments following the bonus rate increase and then continues to rise slowly for a few more periods before stabilizing. Across all treatments financial incentives lead to coordination improvements. The treatments vary only in the strength of this effect.

In periods $11-20$, average minimum effort is consistently higher in the control and "one low, three high" sessions than in the "two low, two high" and "three low, one high" treatments, albeit by a smallish amount. Consistent with these difference in average minimum efforts, average payoffs are also higher for period $11-20$ in the control and "one low, three high" sessions. ${ }^{11}$ There is a mild restart at period 21 caused by the pause to announce that the bonus rate would continue to be $\mathrm{B}=14$. This restart was sufficient to largely close the gap between treatments. Intuitively, a restart is more likely to matter for groups stuck at low effort levels.

\footnotetext{
${ }^{11}$ In any Nash equilibrium the average payoffs cannot be affected by the distribution of costs of efforts as the average cost of effort is the same in all treatments.
} 
Since there are more of these groups in the "two low, two high" and "three low, one high" treatments, the restart has a larger effect for these treatments.

The employee level data displayed in Figure 2 shows a similar pattern, but more accentuated than what Figure 1 shows at the firm level. Following sharp increases for average effort across all treatments in period 11, a persistent gap opens between the average efforts in the in the control and "one low, three high" sessions and average efforts in the "two low, two high" and "three low, one high" treatments. The restart at period 21 is stronger in the employee level data than in the firm level data. Following the restart, average efforts are roughly the same across all four treatments.

To examine the statistical validity of the impressions obtained from the graphs, Table 3 reports regressions on data at both the firm level and the employee level. Data is taken from periods $11-30$, the periods following the bonus rate increase. The dependent variable for the Model 1 is the firm's minimum effort in the current period. For Model 2, the dependent variable is the employee's effort in the current period. There are four times as many observations in Model 2 as in Model 1 since each employee in each period is a separate observation. Model 1 is meant to get at the bottom line of treatment differences, whereas Model 2 allows us to understand the process underlying the improvement of coordination.

Given the ordered and categorical nature of the dependent variables, ordered probit models are used in both regressions. The independent variables are a dummy for periods $21-30$ and interactions between treatment dummies (one low, two low, or three low cost types) and period dummies (periods $11-20$ or periods $21-30$ ). Observations in these regressions are not independent as there are multiple observations from the same firms/employees. We therefore correct the standard errors using a relatively conservative clustering approach to correcting for repeated observations, due to Liang and Zeger (1986). ${ }^{12}$ For firm-level and employee-level regressions, each firm is treated as a separate cluster. This is appropriate for the employee-level regressions since observations from employees in the same firm are not independent.

\section{(Table 3 here)}

The results reported in Model 1 are weak. The base is behavior by firms in the control sessions in periods $11-20$. Only the difference between the controls and the "two low, two high" treatment is statistically significant in periods $11-20$, and then only at the $10 \%$ level.

\footnotetext{
${ }^{12}$ This is the "cluster" option in Stata.
} 
While the magnitude of the treatment effect is roughly the same for the "three low, one high" treatment, it narrowly misses statistical significance. As we would expect given the raw data, none of the treatment effects even approach statistical significance in periods $21-30$ (the comparison here is with the control sessions in periods $21-30$ ).

The modest treatment effects reported in Model 1 confirm what one sees in Figures 1 and 2. Note that we have been quite conservative. If we use a random effects specification to aggressively control for the firm-effects, both of the treatment effects are significant at the $1 \%$ level in periods $11-20$. We can also get both treatment effects to be statistically significant by controlling for employees' choices in periods $1-10$. However, the controls themselves are generally not statistically significant (due to the low variation in employees' choices prior to the bonus rate increase) and getting statistical significance for the treatment effects relies on exactly how the controls are specified. We are leery of cherry-picking the nicest looking regression results, and instead feel that the regression in Model 1 gives a good taste of the data - there appear to be small treatment effects at the firm-level in periods $11-20$, and no treatment differences in periods 21-30.

The employee-level results reported in Model 2 are stronger. The base is behaviour by employees in the control sessions in periods $11-20$. Both the difference between the controls and the "two low, two high" treatment and the difference between the controls and the "three low, one high" treatment are statistically significant at the 5\% level. However, there are again no significant treatment effects in periods $21-30$. The treatment effects are more evident when the behaviour of all employees is considered, rather than using only those employees who are least responsive to the change in bonus rates (e.g. the employees who are determining the minimum effort). ${ }^{13}$

While the presence of asymmetric costs of effort causes differing responses to an increase in the bonus rate, the data provides no support for our initial conjectures that minimum efforts would be higher with asymmetric costs of effort and that this effect would be greatest for the "one low, three high" treatment. We summarize the answer to our first research question as follows.

\footnotetext{
${ }^{13}$ Among other things, this suggests that the effects of asymmetric costs of effort would be more notable at the firm level if a different order statistic game, such as median game, was being played by the employees.
} 
Regularity 1: Increasing the bonus rate causes firms in the control and "one low, three high" sessions to do modestly better than firms in the "two low, two high" and "three low, one high" treatments. This advantage largely disappears with the restart in period 21. The difference between treatments is more pronounced in employee level data than in firm level data.

We now move to the study of leadership. We start by looking at the likelihood of employees becoming "strong leaders," defined as employees who respond to an increase in the bonus rate by raising their effort at least two levels (e.g. 0 hours to 20 hours). Brandts and Cooper (2006) find that the presence of strong leaders plays a central role in determining whether a firm overcomes a history of coordination failure. The same observation holds for the data reported here. The average minimum effort in period 20 is a monotonically increasing function of the number of strong leaders in period $11 .{ }^{14}$ Not only does the number of strong leaders do a good job of predicting whether a firm will eventually overcome coordination failure, it also outperforms other obvious measures of the firm's performance in period 11. To establish this point, we ran an ordered probit regressing firms' minimum efforts in period 20 on the number of strong leaders in round 11, the minimum effort in round 11, and the number of employees who increased their effort in round 11 . The number of strong leaders has a statistically significant effect at the $5 \%$ level, while the minimum effort is only significant at the $10 \%$ level and the number of employees who increased their effort fails to be statistically significant. ${ }^{15}$ The marginal effect on minimum effort in period 20 of adding one strong leader to a firm in period 11 is $37 \%$ greater than the marginal effect of increasing the minimum effort by one level in period 11.

\section{(Table 4 here)}

Now that we know that strong leaders are important we can ask how asymmetric costs affect who becomes a strong leader. Remember that the mechanism through which we anticipated seeing a treatment effect was that low cost types would be obvious candidates for strong leadership. In other words, the asymmetric costs of effort would create a focal point for which employees should be strong leaders. Looking at employee level data, low cost types are actually somewhat less likely than high cost types to become strong leaders in period 11 (50.2\%

\footnotetext{
${ }^{14}$ For $0,1,2,3$, and 4 strong leaders in period 11 , the average minimum efforts in period 20 are 4.0, 8.0, 10.9, 24.1, and 27.0 respectively.

${ }^{15}$ The parameter estimates and standard errors (in parentheses) for the number of strong leaders, minimum effort in period 11, and number of employees increasing their effort in period 11 are .385 (.167), .281 (.147), and .157 (.185) respectively. Note that minimum effort in period 11 has been scaled down by a factor of 10 to facilitate the comparison of marginal effects.
} 
vs. 59.8\%). This result seems counter-intuitive as high cost types have less to gain and more to lose by becoming strong leaders. Indeed, as can be seen in Table 4, the factor driving whether an employee becomes a strong leader isn't the cost of effort but rather cohort size, defined as how many other employees have the same cost of effort as oneself. Table 4 is based on the choices of all 320 employees in period 11. The x-axis gives the cost of effort while the y-axis gives the cohort size. For example, data from a low cost type in the "one low, three high" treatment appears in the first column of the first row while data from a high cost type in this treatment is in the fourth column of the third row. The number reported in each cell in the proportion of employees who were strong leaders in round 11. Increasing the cost of effort does not monotonically affect the likelihood of employees becoming strong leaders, as can be seen from the last row. In contrast, the likelihood of becoming a strong leader is monotonically increasing in the cohort size (see the rightmost column). It is particularly telling to compare the two cases where employees had identical costs of effort but different cohort sizes. ${ }^{16}$ These cells have been highlighted. In both cases, strong leadership is roughly $20 \%$ more likely when the cohort size is greater. $^{17}$

If the only factor affecting whether a firm overcomes coordination failure was the number of strong leaders, we would expect to see the best performance in the controls and the worst performance in the "two low, two high" treatment since these treatments have the largest and smallest cohort sizes respectively. The "one low, three high" and "three low, one high" treatments should perform about the same and should be intermediate cases. A casual examination of the data refutes these predictions - the controls and the "one low, three high" treatment yield almost indistinguishable results as do the "two low, two high" and "three low, one high" treatments. In other words, the two treatments which should be intermediate cases aren't.

The explanation for this lies in a second subtle effect of the treatments on employees' choices. Unlike period 11, in periods $12-20$ it is more important what an employee's cost of effort is than how many other employees share this cost of effort.

\section{(Table 5 here)}

\footnotetext{
${ }^{16}$ The relevant comparisons are between low cost types in the "two low, two high" and "three low, one high" treatments and between high cost types in the "three low, one high" and "two low, two high" treatments.

${ }^{17}$ To clarify, the calculation is ( $\%$ big cohort $/ \%$ small cohort $)-1$, not $\%$ big cohort - \% small cohort.
} 
This effect can be seen in the two panels of Table 5. Both panels report data based on employees' choices in periods $12-20$. The upper panel is based on the choices of employees who were followers in the preceding period - their effort was weakly less than the minimum effort of the other three employees in their firm. The lower panel is drawn from the choices of employees who were leaders in the preceding period - these employees choose an effort level strictly greater than the minimum effort of the other three employees in their firm. The categories along the $\mathrm{x}$-axis and $\mathrm{y}$-axis for each panel are identical to those described above for Table 4. The number in each cell reports the average change in effort.

An identical pattern emerges in both panels of Table 5. Looking at the last row, lower costs of effort are consistently associated with more positive changes in effort (more positive for followers, less negative for leaders). Lower costs of effort make followers more responsive to leaders' efforts and make leaders more persistent in trying to pull followers up to their level. Looking at the rightmost columns of the two panels, no similar effect emerges for changes in the cohort size. $^{18}$

\section{(Table 6 here)}

The regressions reported in Table 6 are designed to put the preceding observations on a firmer statistical footing. The goal is to identify the role of costs of effort and cohort size (again defined as number of other employees with the same cost of effort as oneself) in changes in an individual employee's effort. Data is taken from periods $11-20$, the periods in which the treatment effects are evident. ${ }^{19}$ The dependent variable for both regressions is the employee's effort in the current round. Once again an ordered probit specification is used and standard errors are corrected for clustering at the firm level. As dependent variables the regressions include the lagged effort, the twice lagged effort, and lagged minimum other's effort (e.g. the minimum effort of the firm's other three employees in the previous period). The inclusion of these variables is partially driven by our focus on changes, but is also intended to clarify causality. In particular, we are trying to show that cohort size matters in period 11 but not in later periods. If lagged dependent variables are not included in the regression, a false positive for cohort size can (and does) occur for periods $12-20$. To see why this occurs, suppose that lagged effort plays an important role in determining current effort. If a larger cohort size causes

\footnotetext{
${ }^{18}$ There is a weak relationship for leaders and none for the followers.

${ }^{19}$ The regressions reported on Table 6 have also been run using all data from periods $11-30$. This has little impact on the results.
} 
a bigger increase in effort for period 11, it must also lead to higher effort in periods $12-20$. This is not a direct effect of the larger cohort size on changes in effort in periods $12-20$, but instead an indirect effect on the level of effort in periods $12-20$ coming from the direct effect in period 11. The independent variables of interest are the employee's cost of effort and cohort size. These are interacted with a dummy for period 11 and a dummy for periods $12-20$; the interaction terms allow us to separate the effects of cost of effort and cohort size in period 11 from their effects in later periods. A dummy for period 11 is also included to capture the large effect of changing the bonus rate on effort. In Model 2, the cost of effort for periods $12-20$ is interacted with dummies for whether the employee is a leader (lagged effort $>$ lagged minimum effort of other employees) or a follower (lagged effort $\leq$ lagged minimum effort of other employees). The inclusion of these terms allows us to explore whether the cost of effort matters more in period $12-20$ for followers or for leaders.

Model 1 establishes how period 11 differs from the following periods. Not surprisingly, both the lagged effort and the lagged minimum effort of other employees have large positive (and statistically significant) effects on the current effort level. The twice lagged effort does not significantly impact the current effort level. The dummy for period 11 has a large, positive, and statistically significant parameter estimate. This reflects the immediate jump in effort following the bonus rate increase. For period 11, the effect of the cost of effort does not approach statistical significance while the cohort size has a positive effect that is statistically significant at the $5 \%$ level. For periods $12-20$, the cost of effort has a negative effect that is statistically significant at the $1 \%$ level while the cohort size no longer has a statistically significant effect. Consistent with our previous observations, the cohort size only plays an important role in period 11 when employees are responding to the change in the bonus rate. Cost of effort has little impact on this initial reaction but plays an important role in subsequent periods.

Model 2 clarifies the role of costs of effort in periods $12-20$. The interaction term between costs of effort for periods $12-20$ and whether the employee is a leader is tiny and nowhere close to statistical significance. The other interaction term, between costs of effort in periods $12-20$ and whether the employee is a follower is four times as large and significant at 
the $1 \%$ level. The cost of effort in periods $12-20$ acts primarily by making followers less responsive to the actions of leaders. ${ }^{20}$

Regularity 2: Larger cohort size makes employees more responsive to the bonus rate increase in period 11 but does not affect their behavior in later periods. Higher costs of effort do not affect employees' response to the bonus rate increase in period 11 but make followers less likely to increase their effort in later periods.

The differing effects of cohort size and costs of effort provide an explanation for why behavior differs between the "one low, three high" and "three low, one high" treatments. In some sense the "one low, three high" treatment is a best case scenario. The three high cost types have a relatively large cohort so it is likely that there will be multiple strong leaders. While the low cost types are relatively unlikely to be strong leaders, they should be responsive followers due to their low costs. Thus, all the ingredients for a successful turnaround are in place. In contrast, the "three low, one high" treatment lacks a critical element. While the large cohort of low cost types should generate a good supply of strong leaders, the high cost types are unlikely to be either strong leaders or responsive followers. High cost types in the "three low, one high" treatment are prime candidates for scuttling a turnaround.

\section{(Figure 3 here)}

Figure 3 displays employees' average efforts in periods $10-20$, broken down by type, in the "one low, three high" and "three low, one high" treatments. The patterns described above, while subtle, are clearly visible. In the "one low, three high" treatment, the immediate reaction to the bonus rate increase is larger for the high cost types but the low cost types are responsive to leadership from high cost types, increasing to a higher average effort than the high cost types in period 12 (as well as the following periods). The "three low, one high" treatment shows a different pattern. Once again the type with a large cohort, the low cost types in this case, reacts more strongly to the increase in the bonus rate. However, in this case the other type is not responsive to their leadership. Average effort for high cost types in the "three low, one high" treatment falls between periods 11 and 12. Rather than rising to meet the leadership of low cost types, the high cost types pull the low cost types down to their level. Thus, the differences

\footnotetext{
${ }^{20}$ This differential effect is robust to a variety of different specifications. The discrepancy between Table 5 , where no such effect is obvious, and Table 6 is due to using effort rather than change of effort as the dependent variable. There is regression to the mean in the data which Table 5 isn't accounting for.
} 
between the "one low, three high" and "three low, one high" treatments are driven by differences in the responsiveness of the less frequent type.

\section{Conclusions}

The coordination problems contained in the turnaround game are like the layers of an onion. The core problem is that for employees to achieve high payoffs, all must coordinate on high effort levels. Because unilateral moves to higher effort levels are unlikely to succeed, employees must find some way of coordinating with respect to when to move to higher levels. Previous work shows that, with identical employees, increases in the bonus rate can act as the necessary coordination device at this level of the problem. Given that successful escapes from coordination traps take place gradually with strong leaders pulling laggards after them, employees face an additional coordination problem of determining who the leaders in this process ought to be. With symmetric effort costs there may be individuals spontaneously emerging as the leaders of this growth process, but there isn't anything about the game per se that suggests who these leaders ought to be. Because asymmetric costs serve to differentiate groups of employees within the firm, we had speculated that these could act as a focal point to ease the coordination problem of who should lead.

The results are more complex than our initial intuition would suggest. Asymmetric costs do not improve firms' abilities to overcome coordination failure. If anything, the opposite is true. Underlying the weak treatment effects are strong interactions between the structure of effort costs and the choices of individual employees. As expected, the process of overcoming coordination failure is led by a subset of employees who take the initiative and pull others out of the trap. These leaders are not the low-cost employees, but those whose costs are more frequent in the group. By itself, this cohort size effect implies that symmetric costs should be the best case for escaping the coordination trap. Somewhat mitigating the cohort size effect is a second effect that higher cost employees tend to be less responsive as followers. When these effects work in opposite directions, as in the "three low, one high" treatment, the lack of responsive followers can overcome the enhanced efforts of leaders.

The strong cohort size effect we observe in our data is quite interesting, but we can only speculate about its cause. One possibility is that having a large cohort eases the common knowledge problem at the heart of coordination games. An employee should only raise his effort

if he believes that others will raise their effort as well. He should only expect these increases if 
he believes that others believe he will raise his effort, etc. Believing that others will make the same increases as oneself may be easier if others are more like oneself. In other words, similarity may make subjects feel they have some insight into the likely reasoning of other players. A second possibility is that cohort size effects are due to greater group identity. If an employee feels more akin to his fellow employees, he may be more willing to try and help them by taking a leadership role. Having the same cost as most of the other employees could lead to this sense of kinship.

The cohort size effect we observe in coordination games could well be present in other frequently studied environments. Public goods games are an obvious candidate. If we believe that most individuals are conditional cooperators, the standard VCM public goods game takes on the character of a coordination game. With asymmetric costs of contributing to the public good, we would predict that subjects with a large cohort size should initially (ceteris paribus) be more willing to contribute to the public good. Of course, this does not imply that contributions will necessarily be higher with asymmetric costs of contribution. The same types of subtle interactions we observe in weak line games are going to be present in public goods games. Once again, the price of a larger cohort size may be laggards (either due to small cohort size or high costs) who drag the group down to their level. 


\section{References}

Blume, A. and A. Ortmann (2005), "The Effects of Costless Pre-play Communication: Experimental Evidence from Games with Pareto-ranked Equilibria," forthcoming Journal of Economic Theory.

Bornstein, G., U. Gneezy, and R. Nagel (2002), "The Effect of Intergroup Competition on Group Coordination: An Experimental Study," Games and Economic Behavior, 41,1,1 - 25.

Brandts, J. and D. Cooper (2005), "It's What You Say No What You Pay. An Experimental Study of Manager-Employee Relationships in Overcoming Coordination Failure," http://www.iae-csic.uab.es/brandts/.

Brandts, J. and D. Cooper (2006), "A Change Would Do You Good. An Experimental Study on How to Overcome Coordination Failure in Organizations," American Economic Review, in press.

Camerer, C. (2003) Behavioral Game Theory: Experiments in Strategic Interaction, Princeton, NJ: Princeton University Press.

Camerer, C. and M. Knez (1994), "Creating 'expectational assets' in the Laboratory: 'Weakest Link' coordination games,” Strategic Management Journal,_15, 101-119.

Croson, R. T. A., E. Fatas and T. Neugebauer (2005). "Excludability and Contribution: A Laboratory Study on Team Production", mimeo.

Fatas, E., T. Neugebauer and J. Perote (2006): "Within team competition in the minimum game", Pacific Economic Review, 11, 2, 247-266.

Knez, Marc and Colin Camerer (2000), "Increasing Cooperation in Prisoner's Dilemmas by Establishing a Precedent of Efficiency in Coordination Games," Organizational Behavior and Human Decision Processes, 82, 2, $194-216$.

Cooper, D. J. and J. H. Kagel (2003), "Lessons Learned: Generalizing Learning Across Games," American Economic Review, 93, 202-207.

Liang, K.-Y., and S.L. Zeger (1986), "Longitudinal Data Analysis Using Gerealized Linear Models," Biometrika, 73, 13-22.

Van Huyck, J., R. Battalio, and R. Beil (1990), "Tacit Coordination Games, Strategic Uncertainty, and Coordination Failure," American Economic Review, 80, 234-248.

Weber, R. (2006), "Managing Growth to Achieve Efficient Coordination in Large Groups," American Economic Review, 96, 1, $114-126$. 
Weber, R., C. F. Camerer and M. Knez (2004), "Timing an Virtual Observability in Ultimatum Bargaining and 'Weak Link' Coordination Games,” Experimental Economics, 7, 25-48.

Weber, R., C. Camerer , Y. Rottenstreich and M. Knez (2001), "The Illusion of Leadership: Misattribution of Cause in Coordination Games," Organizational Science, 12, 582-598. 


\section{Table 1}

Employee i's Payoff Tables for B=8

\begin{tabular}{|c|c|c|c|c|c|c|}
\hline & \multicolumn{4}{|c|}{$C_{i}=1$} & \\
\hline & & \multicolumn{5}{|c|}{$\begin{array}{l}\text { Minimum Effort } \\
\text { by Other Employees }\end{array}$} \\
\hline & & 0 & 10 & 20 & 30 & 40 \\
\hline \multirow{5}{*}{ 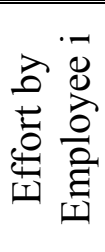 } & 0 & 200 & 200 & 200 & 200 & 200 \\
\hline & 10 & 190 & 330 & 330 & 330 & 330 \\
\hline & 20 & 180 & 320 & 460 & 460 & 460 \\
\hline & 30 & 170 & 310 & 450 & 590 & 590 \\
\hline & 40 & 160 & 300 & 440 & 580 & 720 \\
\hline
\end{tabular}

\begin{tabular}{|c|c|c|c|c|c|c|}
\hline & \multicolumn{4}{|c|}{$C_{i}=9$} & \\
\hline & & \multicolumn{5}{|c|}{$\begin{array}{c}\text { Minimum Effort } \\
\text { by Other Employees }\end{array}$} \\
\hline & & 0 & 10 & 20 & 30 & 40 \\
\hline \multirow{5}{*}{ 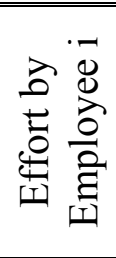 } & 0 & 200 & 200 & 200 & 200 & 200 \\
\hline & 10 & 110 & 250 & 250 & 250 & 250 \\
\hline & 20 & 20 & 160 & 300 & 300 & 300 \\
\hline & 30 & -70 & 70 & 210 & 350 & 350 \\
\hline & 40 & -160 & -20 & 120 & 260 & 400 \\
\hline
\end{tabular}


Table 2

Summary of Experiments

\begin{tabular}{|c|c|c|c|c|}
\hline Treatment Name & Symmetric & $\begin{array}{c}\text { One Low } \\
\text { Three High }\end{array}$ & $\begin{array}{l}\text { Two Low } \\
\text { Two High }\end{array}$ & $\begin{array}{l}\text { Three Low } \\
\text { One High }\end{array}$ \\
\hline \multicolumn{5}{|c|}{ Treatment Variables } \\
\hline Player 1 Cost & 7 & 1 & 5 & 5 \\
\hline Player 2 Cost & 7 & 9 & 5 & 5 \\
\hline Player 3 Cost & 7 & 9 & 9 & 5 \\
\hline Player 4 Cost & 7 & 9 & 9 & 13 \\
\hline $\begin{array}{c}\text { Bonus Rate } \\
\text { (Blocks 1 / Blocks 2 \& 3) }\end{array}$ & $8 / 14$ & $8 / 14$ & $8 / 14$ & $8 / 14$ \\
\hline $\begin{array}{c}\text { Number of Firms } \\
\text { (Number of sessions) } \\
\end{array}$ & $\begin{array}{c}19 \\
(2 \text { sessions }) \\
\end{array}$ & $\begin{array}{c}20 \\
(2 \text { sessions }) \\
\end{array}$ & $\begin{array}{c}21 \\
(2 \text { sessions }) \\
\end{array}$ & $\begin{array}{c}20 \\
(3 \text { sessions }) \\
\end{array}$ \\
\hline \multicolumn{5}{|c|}{ Descriptive Statistics } \\
\hline $\begin{array}{c}\text { Average Minimum Effort } \\
\text { Round } 10\end{array}$ & 4.21 & 0.00 & 0.00 & 0.00 \\
\hline $\begin{array}{l}\text { Average Minimum Effort } \\
\text { Block } 2\end{array}$ & 19.11 & 18.55 & 12.57 & 12.7 \\
\hline $\begin{array}{l}\text { Average Minimum Effort } \\
\text { Block } 3\end{array}$ & 19.16 & 21.55 & 18.90 & 17.3 \\
\hline $\begin{array}{l}\text { Average Effort } \\
\text { Block } 2\end{array}$ & 24.76 & 24.6 & 17.58 & 16.75 \\
\hline $\begin{array}{l}\text { Average Effort } \\
\text { Block } 3\end{array}$ & 23.93 & 24.15 & 21.12 & 19.23 \\
\hline $\begin{array}{l}\text { Average Payoff } \\
\text { Block } 2\end{array}$ & 294 & 289 & 255 & 264 \\
\hline $\begin{array}{l}\text { Average Payoff } \\
\text { Block } 3\end{array}$ & 301 & 335 & 318 & 310 \\
\hline
\end{tabular}

Notes: All firms include four employees. Block 1 is rounds $1-10$, block 2 is rounds $11-20$, and block 3 is rounds $21-30$. 
Table 3

Ordered Probits, Treatment Effects

\begin{tabular}{|c|c|c|}
\hline Dependent Variable & Minimum Effort (Firm) & Effort (Employee) \\
\hline \hline Number of Observations & 1600 & 6400 \\
\hline Number of Clusters & 80 & 80 \\
\hline \hline Variable & Model 1 & Model 2 \\
\hline Rounds $21-30$ & .004 & $(.043$ \\
& $(.154)$ & -.006 \\
* One Low Cost Type & -.060 & $(.263)$ \\
\hline Rounds 21 30 & $(.282)$ & .001 \\
$*$ One Low Cost Type & .142 & $(.338)$ \\
\hline Rounds 11-20 & $(.367)$ & -.510 \\
$*$ Two Low Cost Types & $-.467^{* *}$ & $(.245)$ \\
\hline Rounds 21 - 30 & $(.270)$ & -.235 \\
$*$ Two Low Cost Types & -.062 & $(.343)$ \\
\hline Rounds 11 - 20 & $(.363)$ & -.513 \\
$*$ Three Low Cost Types & -.400 & $(245)$ \\
\hline Rounds 21 - 30 & $(.259)$ & -.318 \\
$*$ Three Low Cost Types & -.109 & $(.308)$ \\
\hline \hline Log Likelihood & $(.329)$ & -9790.57 \\
\hline \hline
\end{tabular}

Note: Standard errors are corrected for clustering at the firm level. ***,**, and * denote statistical significance at the $\mathrm{p}<.01, \mathrm{p}<.05$, and $\mathrm{p}<.10$ levels respectively. 
Table 4

Proportion of Strong Leaders in Period 11

\begin{tabular}{|c|c|c|c|c|c|c|c||}
\cline { 3 - 7 } \multicolumn{2}{c|}{} & \multicolumn{7}{c|}{ Cost of Effort } \\
\cline { 2 - 8 } \multicolumn{2}{c|}{} & 1 & 5 & 7 & 9 & 13 & All \\
\hline \hline \multirow{4}{*}{ Cohort Size } & 0 & .50 & --- & --- & --- & .40 & .45 \\
\cline { 2 - 8 } & 1 & --- & .43 & --- & .57 & --- & .50 \\
\cline { 2 - 8 } & 2 & --- & 55 & --- & .68 & --- & .62 \\
\cline { 2 - 8 } & 3 & --- & --- & .63 & --- & --- & .63 \\
\cline { 2 - 8 } & All & .50 & .50 & .63 & .64 & .40 & --- \\
\hline
\end{tabular}

Note: Cohort size is defined as the number of other employees in the firm with the same cost of effort as oneself. 
Table 5

Average Change of Effort in Periods 12-20

Followers (Lagged Effort $\leq$ Lagged Minimum Effort of Other Employees)

\begin{tabular}{|c||c|c|c|c|c|c|c||}
\multicolumn{2}{c|}{} & \multicolumn{7}{c|}{ Cost of Effort } \\
\cline { 2 - 8 } \multicolumn{2}{c|}{} & \multicolumn{1}{c|}{} & \multicolumn{7}{c||}{ All } \\
\hline \hline \multirow{3}{*}{ Cohort Size } & 0 & 2.66 & --- & --- & --- & 1.22 & 1.83 \\
\cline { 2 - 8 } & 1 & --- & 3.39 & --- & 1.95 & --- & 2.60 \\
\cline { 2 - 8 } & 2 & --- & 2.13 & --- & 2.27 & --- & 2.20 \\
\cline { 2 - 8 } & 3 & --- & --- & 1.91 & --- & --- & 1.91 \\
\cline { 2 - 8 } & All & 2.66 & 2.62 & 1.91 & 2.13 & 1.22 & --- \\
\hline
\end{tabular}

Leaders (Lagged Effort > Lagged Minimum Effort of Other Employees)

\begin{tabular}{|c|c|c|c|c|c|c|c||}
\multicolumn{2}{c|}{} & \multicolumn{7}{c|}{ Cost of Effort } \\
\cline { 2 - 8 } \multicolumn{1}{c|}{} & 1 & 5 & 7 & 9 & 13 & All \\
\hline \hline \multirow{4}{*}{ Cohort Size } & 0 & -4.37 & --- & --- & --- & -6.56 & -5.05 \\
\cline { 2 - 8 } & 1 & --- & -4.74 & --- & -6.69 & --- & -5.54 \\
\cline { 2 - 8 } & 2 & --- & -6.70 & --- & -5.94 & --- & -6.12 \\
\cline { 2 - 8 } & 3 & --- & --- & -6.13 & --- & --- & -6.12 \\
\cline { 2 - 8 } & All & -4.37 & -5.59 & -6.13 & -6.21 & -6.56 & --- \\
\hline
\end{tabular}

Note: Cohort size is defined as the number of other employees in the firm with the same cost of effort as oneself. 
Table 6

Ordered Probits, Costs vs. Compatriots

(Dependent Variable: Employee Effort)

\begin{tabular}{|c|c|c|}
\hline Variable & Model 1 & Model 2 \\
\hline Lagged Effort & $\begin{array}{l}.064^{* * * *} \\
(.004)\end{array}$ & $\begin{array}{l}.058^{\text {**** }} \\
(.005)\end{array}$ \\
\hline Twice Lagged Effort & $\begin{array}{l}-.004 \\
(.003) \\
\end{array}$ & $\begin{array}{l}-.004 \\
(.003) \\
\end{array}$ \\
\hline $\begin{array}{c}\text { Lagged Minimum } \\
\text { Other's Effort }\end{array}$ & $\begin{array}{l}.074^{\text {***** }} \\
(.006)\end{array}$ & $\begin{array}{l}.080^{\text {**** }} \\
(.007)\end{array}$ \\
\hline Period 11 & $\begin{array}{c}1.495^{* * * *} \\
(.432)\end{array}$ & $\begin{array}{c}1.470^{* * * *} \\
(.432)\end{array}$ \\
\hline $\begin{array}{c}\text { Cost of Effort * } \\
\text { Period } 11\end{array}$ & $\begin{array}{c}.017 \\
(.032) \\
\end{array}$ & $\begin{array}{l}.016 \\
(.032) \\
\end{array}$ \\
\hline Cohort Size * Period 11 & $\begin{array}{l}.239^{* *} \\
(.114)\end{array}$ & $\begin{array}{l}.242^{* *} \\
(.114)\end{array}$ \\
\hline $\begin{array}{l}\text { Cost of Effort } * \\
\text { Periods } 12-20\end{array}$ & $\begin{array}{l}-.026^{* * * *} \\
(.007)\end{array}$ & \\
\hline $\begin{array}{c}\text { Cost of Effort } * \\
\text { Periods } 12-20 * \text { Leader }\end{array}$ & & $\begin{array}{l}-.009 \\
(.009)\end{array}$ \\
\hline $\begin{array}{c}\text { Cost of Effort } * \\
\text { Periods } 12-20 * \text { Follower }\end{array}$ & & $\begin{array}{c}-.034^{* * *} \\
(.008)\end{array}$ \\
\hline Cohort Size * Period $12-20$ & $\begin{array}{l}-.007 \\
(.031) \\
\end{array}$ & $\begin{array}{l}-.011 \\
(.031) \\
\end{array}$ \\
\hline Log Likelihood & -3164.40 & -3160.79 \\
\hline
\end{tabular}

Note: Both regressions include 3200 observations from 320 employees. Standard errors are corrected for clustering at the firm level. $* * *, * *$, and $*$ denote statistical significance at the $\mathrm{p}<$ $.01, \mathrm{p}<.05$, and $\mathrm{p}<.10$ levels respectively. Cohort size is defined as the number of other employees in the firm with the same cost of effort as oneself. 


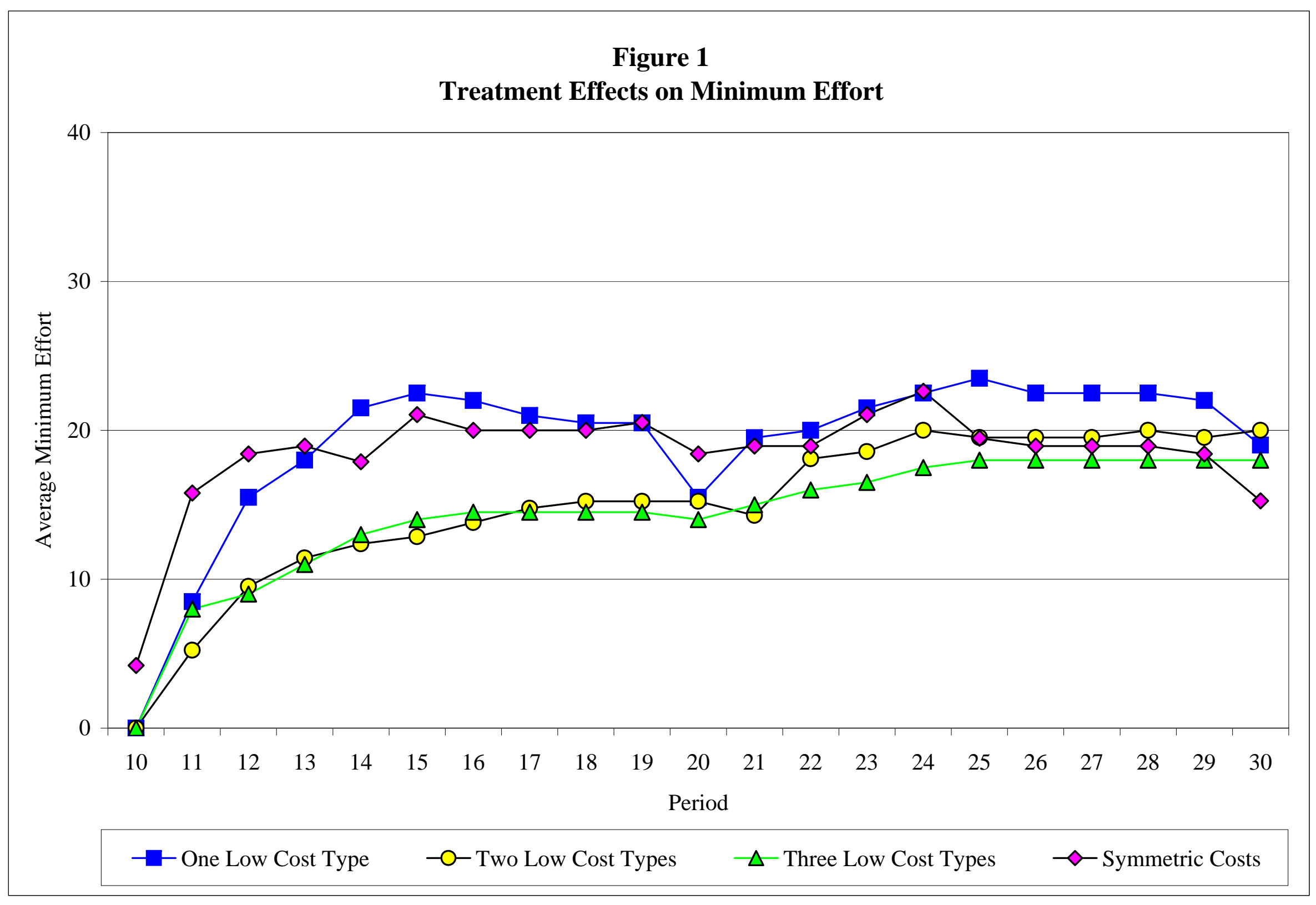




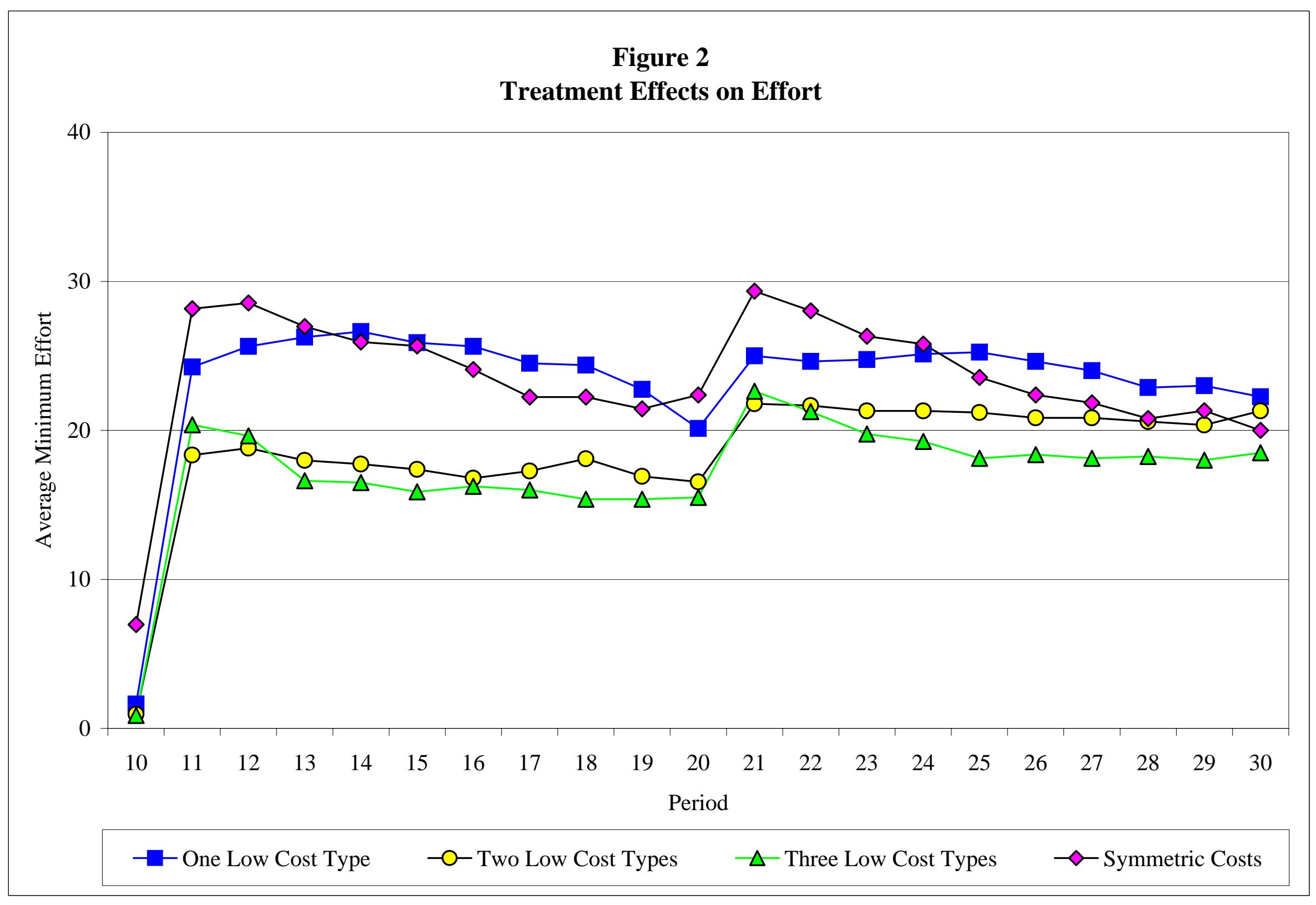


Figure 3

Responses to the Bonus Rate Increase by Treatment and Type

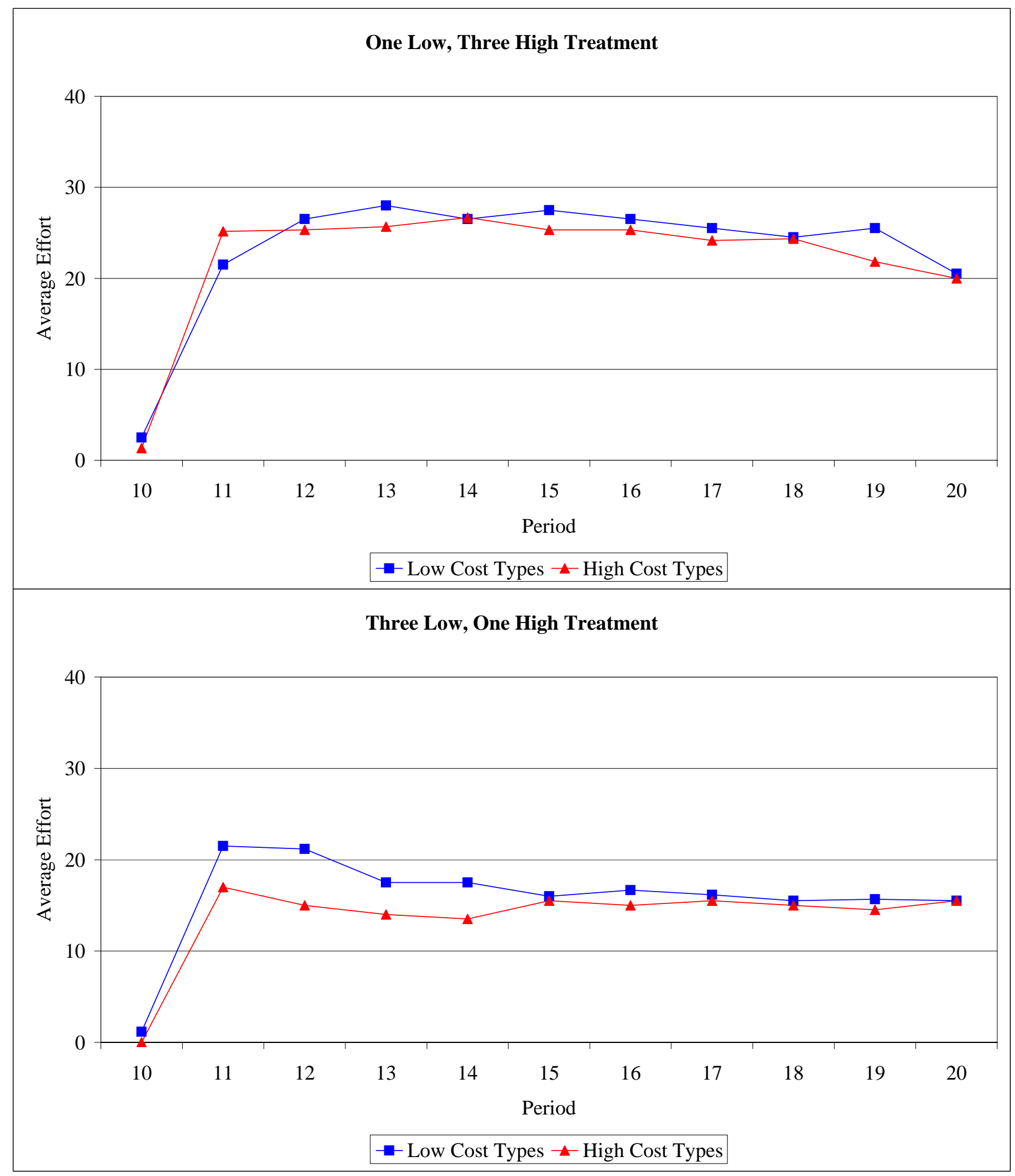

